\title{
Possible Roles of Ectophosphatases in Host-Parasite Interactions
}

\author{
Marta T. Gomes, ${ }^{1,2}$ Angela H. Lopes, ${ }^{3}$ and José Roberto Meyer-Fernandes ${ }^{1,2}$ \\ ${ }^{1}$ Instituto de Bioquímica Médica, Universidade Federal do Rio de Janeiro, CCS, Bloco H, Cidade Universitária, \\ Ilha do Fundão, 21941-902 Rio de Janeiro, RJ, Brazil \\ ${ }^{2}$ Instituto Nacional de Ciência e Tecnologia de Biologia Estrutural e Bioimagem (INCTBEB), CCS, Bloco H, \\ Cidade Universitária, 21941-902 Rio de Janeiro, RJ, Brazil \\ ${ }^{3}$ Instituto de Microbiologia Professor Paulo de Góes, Universidade Federal do Rio de Janeiro, CCS, Bloco H, \\ Cidade Universitária, Ilha do Fundão, 21941-902 Rio de Janeiro, RJ, Brazil
}

Correspondence should be addressed to José Roberto Meyer-Fernandes, meyer@bioqmed.ufrj.br

Received 22 November 2010; Revised 7 February 2011; Accepted 1 March 2011

Academic Editor: Barbara Papadopoulou

Copyright ( $) 2011$ Marta T. Gomes et al. This is an open access article distributed under the Creative Commons Attribution License, which permits unrestricted use, distribution, and reproduction in any medium, provided the original work is properly cited.

The interaction and survival of pathogens in hostile environments and in confrontation with host immune responses are important mechanisms for the establishment of infection. Ectophosphatases are enzymes localized at the plasma membrane of cells, and their active sites face the external medium rather than the cytoplasm. Once activated, these enzymes are able to hydrolyze phosphorylated substrates in the extracellular milieu. Several studies demonstrated the presence of surface-located ectophosphatases in a vast number of pathogenic organisms, including bacteria, protozoa, and fungi. Little is known about the role of ecto-phosphatases in host-pathogen interactions. The present paper provides an overview of recent findings related to the virulence induced by these surface molecules in protozoa and fungi.

\section{Introduction}

Cells are exposed to diverse environmental stimuli throughout their cycles in all biological systems. Protein phosphorylation and dephosphorylation are central events in cell recognition of external and internal signals, leading to specific responses. While protein kinases transfer a phosphate group from ATP to a protein (i.e., phosphorylate), protein phosphatases catalyze the removal of phosphate groups from specific residues of proteins (i.e., dephosphorylate) $[1,2]$. The balance between the antagonistic activities of protein kinases and phosphatases are responsible for many cellular functions, including metabolic pathways, cell-cell communication, proliferation, and gene transcription [3].

The complete genome sequencing of various microorganisms made it possible to assemble the kinome and phosphatome of a few trypanosomatids $[4,5]$. These strategies have brought new perspectives of researches in the areas of biochemistry, physiology, and genetics, providing knowledge about the microorganisms' life cycles, as well as predicting diagnostic biomarkers, novel drug targets and vaccine candidates against parasitic infections.
Parasites engage a plethora of surface and secreted molecules in order to attach and enter mammalian cells. Some of these molecules are involved in triggering specific signaling pathways both in the parasite and the host cell, which are critical for parasite entry and survival [6]. Plasma membranes of cells contain enzymes that are oriented with their active sites facing the external medium rather than the cytoplasm, which are important for host-parasite interactions $[7,8]$. In the case of an ectoenzyme other criteria can be included as: (1) the enzyme has to act on extracellular substrate, (2) cellular integrity is maintained during enzyme activity, (3) the products are released extracellularly, (4) the enzyme is not released to the extracellular environment; and (5) the enzyme activity can be modified by nonpenetrating reagents $[7,8]$. Supporting this idea, the presence of surfacelocated phosphatases, called ecto or extracytoplasmic phosphatases have been characterized in several microorganisms. However, the physiological roles of these enzymes in these cells are not well established yet. In eukaryotes, the most predominant phosphorylation sites are detected on serine, threonine and tyrosine residues. Thus, catalytic signature 
motifs and substrate preferences classified these proteins into four major groups: phosphoprotein phosphatases (PPPs), metallo-dependent protein phosphatases (PPMs), aspartatebased phosphatases with a DxDxT/V motif (the members of these three groups are Ser/Thr specific phosphatases) and the distinct group of protein tyrosine phosphatases (PTPs) [9]. Protein tyrosine phosphatases belong to three evolutionarily unrelated classes: protein tyrosine phosphatases (PTPs), Cdc25 and low molecular weight phosphatases (LMWPTPs), which have a common motif (CX5R) in their catalytic sites [10]. The classical PTPs are classified, depending on the presence or absence of transmembrane domains, into receptor or nonreceptor type phosphatase groups.

The use of inhibitors, divalent cations, metal chelators and different $\mathrm{pH}$ range has also been an important tool for classification of these enzymes. Likewise, phosphatases may be acid or alkaline according to their $\mathrm{pH}$ range for activity. The optimum $\mathrm{pH}$ for acid ectophosphatases lies on the acid range ( $\mathrm{pH}$ values between 4.5 and 5.5), while the optimum $\mathrm{pH}$ for alkaline ectophosphatases lies on the alkaline range ( $\mathrm{pH}$ values between 8.0 and 9.0) $[9,10]$. The inhibitors classically used include: phosphotyrosine phosphatase inhibitors ammonium molybdate and sodium orthovanadate; acid phosphatase inhibitor sodium fluoride $(\mathrm{NaF})$; secreted phosphatase inhibitor sodium tartrate; alkaline phosphatase inhibitor levamisole and phosphoserine/threonine phosphatases inhibitors okadaic acid and microcystin-LR [11-13]. Several biological roles for ectophosphatases have been proposed. These enzymes may provide microorganisms with a source of inorganic phosphate by hydrolyzing phosphomonoester metabolites [1315] protect them upon entering the macrophage by suppressing the respiratory burst [16], as well as play a role in cell differentiation [17], infection of host cells [18-20] and protecting the cells from acidic conditions by buffering the periplasmic space with phosphate released from polyphosphates [21]. Some protein phosphatases have been described as being active towards low molecular weight nonproteic phosphoesters, such as alkyl and aryl phosphates, including the phosphotyrosine analog, p-nitrophenylphosphate [18]. From a general standpoint, the surface accessibility of ectophosphatases, along with protein phosphorylated on serine/threonine/tyrosine residues at the cell surface make this set of enzymes a key tool for the survival of pathogens in hostile environments and escaping the host immune responses [19, 22-24]. In this review, we describe the role of ectophosphatase activities in host-parasite interactions, particularly ectophosphatases in parasitic protozoa and fungi.

\section{Ectophosphatase Activities in Protozoa Infection}

Little is still known about the physiological role of protein phosphatase activity in trypanosomatids, even though the first demonstration of this activity in Trypanosoma brucei and T. cruzi took place in 1972 [25]. The kinetoplastid parasites have complex life cycles and some of their life forms are difficult to grow in culture, which may represent a problem for studying ectophosphatases. Pathogenic trypanosomatids have at least two different host environments in their life cycles, an insect vector and a mammal. Also, each trypanosomatid genus has different abilities to survive and reproduce in such hosts. For instance, Leishmania spp. are intracellular parasites, seeking to invade macrophages. On the other hand, T. cruzi invades and replicates in many cell-types, including macrophages, fibroblasts and myocytes. T. brucei is an exclusively extracellular parasite that resides in the bloodstream of the mammalian host. As the life cycles of these parasites take place through widely different environments, frequent and substantial adaptive changes are required in many cell processes, resulting in changes in gene expression, protein levels and protein modifications [26, 27]. Along with those, cell surface components play a key role in the survival of protozoan parasites in hostile environments and in confrontation with host immune responses. Since, these flagellates have an unusual composition of phosphatases with the PTP family being greatly reduced while the STP family is expanded by comparison with human phosphatases. The low similarity to their vertebrate counterparts indicates that these enzymes may be potentially suitable targets for development of potent inhibitors with minimal effects on the physiology of mammalian hosts [5].

Under these conditions, ectophosphatases play an important role in the interaction of cells with their surroundings, especially because their catalytic sites face the extracellular milieu. Ecto-phosphatases has been reported in some protozoa parasites, such as $T$. rhodesiense [28], T. congolense [29], T. brucei [30, 31], T. cruzi [32], T. rangeli [13, 33], some Leishmania species [11, 34], Herptomonas muscarum muscarum [35], Phytomonas spp. [36, 37], Entamoeba histolytica [38], Giardia lamblia [39] and Trichomonas vaginalis [40]. In general, these ectoenzymes are usually reported to have optimum activities in the acidic $\mathrm{pH}$ range, and they are therefore also known as membrane-bound acid phosphatases $[28,29]$. In trypanosomatids, the low optimum $\mathrm{pH}$ and the surface location of these enzymes suggest its role in an acidic microenvironment and/or a close relationship with lysosomal digestion, possibly reflecting an adaptation of the parasite to the intracellular or phagosomal environment $[41,42]$.

Cloning and purification of an acidic phosphatase in T. brucei suggest that these enzymes may represent a new ectophosphatase class lacking homology to other known phosphatases [31]. It seems that these proteins are related to the regulation of $T$. brucei development, since these acidic phosphatases are expressed in bloodstream forms, but not in the insect procyclic form [31]. Likewise, an ectophosphatase activity on the surface of intact procyclic and bloodstream forms of $T$. brucei was demonstrated by Fernandes et al. [43, 44]. These enzymes show different behavior, like sensitivity to inhibitors and metal interference. Similarly, an ectophosphatase was also cloned and purified in $L$. mexicana, where it was located in the endosomal/lysosomal compartment between the flagellar pocket and the nucleus in wild-type promastigotes, and the overexpression of this protein leads to its abundant exposure on the cell surface $[45,46]$. The same was seen with membrane-bound acid 
phosphatase from the bloodstream form of T. brucei, where the enzyme is supposed to participate in the maintenance of endocytosis/exocytosis and in differentiation to the insect stage [47]. The wide distribution of acid phosphatases on the cell may reflect some physiological adaptation for parasite survival within the host.

In this scenario, ectophosphatase activities were identified at the cell surface of all T. cruzi development stages: epimastigote [48], trypomastigote [18] and amastigote forms $[18,32]$. It seems that in amastigote forms these enzymes are magnesium-dependent and can hydrolyse phosphoaminoacids and phosphoproteins under physiological conditions $[18,32]$. This behavior could facilitate the interaction between parasite and host cells, once T. cruzi phosphatases leads to dephosphorylation of proteins important in the signal transduction pathway or cycle regulation of this protozoan parasite. Supporting this idea, Y strain presents $\mathrm{Mg}^{2+}$-dependent ectophosphatase activity, while Colombiana strain expresses $\mathrm{Mg}^{2+}$-independent activity [48]. Among other characteristics, members of these two groups have different patterns of behavior considering their ability to infect mammalian host cells. Parasites from the Colombiana strain appeared to be more infective to myoblasts than those from the Y strain, while the latter is more infective towards macrophages than the parasites of the Colombiana strain [49]. Intriguingly, platelet-activating factor (PAF), a phospholipid mediator involved in differentiation cellular in T. cruzi, induces the secretion of an ectophosphatase in these parasites, associating this event with the infectivity of the parasite [50].

Addition of sodium orthovanadate (a protein tyrosine phosphatase inhibitor) in the interaction medium from $L$. amazonensis and macrophages significantly increased parasite binding and internalization, suggesting that Leishmania induces tyrosine phosphorylation $[24,51]$. Under these conditions, protein tyrosine kinase-linked pathways regulate the Leishmania promastigote invasion, which ectophosphatase activity upregulate $L$. amazonensis binding ligands for macrophage receptors and intracellular survival within these cells $[24,51,52]$. It seems that during macrophage infection by Leishmania the parasite attenuates MAP kinase signaling, as well as c-FOS and iNOS expression in macrophages, stimulating the phosphotyrosine phosphatase activity in these cells [53-55]. These findings suggest a mechanism for macrophage deactivation used by Leishmania spp. and possibly by other intracellular pathogens as a strategy of the parasites to interact and survive within their hosts. In L. donovani tyrosine phosphatase activity was also detected, suggesting that tyrosine phosphorylation occurs, though not via receptor tyrosine kinase or tyrosine kinase-like activities but very likely due to the activity of atypical and/or dual specific kinases [56]. Futhermore, a membrane-bound PTP has been describe in L. major metacyclic promastigote forms, which is translocated to the cytoplasm in promastigotes. In spite of the increased level of the molecule in metacyclic promastigotes compared to the procyclic forms, the specific activity of the enzyme was lower in metacyclic than in procyclic promastigotes [42]. Interestingly, a protein tyrosine phosphatase, has been identified in L. major ( $L m P T P 1)$ that allows amastigotes forms to survive in mice [57]. Although its biological function is unclear, this may be an important factor in virulence, enabling the invading pathogen to survive in a host. Ecto-phosphatase isolated from $L$. donovani promastigotes inhibits the production of superoxide anions in intact human neutrophils [16]. This activity could contribute to the survival of the parasite within the host, we can hypothesize that parasites with greater ectophosphatase activity would be more resistant to oxidative bursts from the host's immune system.

The role of ectophosphatases in invasive amoebiasis is still unknown, even though two acid phosphatases have been characterized in these parasites: a membrane-bound acid phosphatase (MAP) $[58,59]$ and a phosphatase that is secreted to the culture medium (SAP), as well as to the cell interface in amoebic liver abscess $[60,61]$. These enzymes may be associated with cellular adhesion processes, since the invasive E. histolytica showed much higher ectophosphatase activity when compared to the noninvasive counterpart and the free-living E. moshkovskii [62].

\section{Ectophosphatase Activities in Fungi Infection}

The fungal cell wall is a compact albeit dynamic structure that plays important roles in several biological processes determining cell shape, morphogenesis, reproduction, cellcell and cell-matrix interactions, osmotic and physical protection. Several different cell wall components have been characterized such as specific enzymatic activities, heatshock proteins, glycosphingolipids (GSL), melanin, histone and integrin-like proteins [63]. These components have been exhaustively studied as putative targets for drug and immunotherapy.

Even though the roles of ectophosphatases in fungi are still largely unknown, the cellular distribution of ectophosphatases, together with their ability to interfere with physiologic processes through the removal of phosphate groups of regulatory proteins, suggest a task for these molecules during the infection of host cells. The presence of surfacelocated acid phosphatases, called ecto or extracytoplasmic phosphatases has been demonstrated in nonpathogenic yeast Saccharomyces cerevisiae [64] and in pathogenic species such as Candida albicans [20], Candida parapsilosis [19, 65], Sporothrix schenckii [66], Aspergillus fumigatus [67], Fonsecaea pedrosoi [22, 68], Cryptococcus neoformans [23] and Pseudallescheria boydii [69].

Futhermore, most of the phosphatases synthesized under Pi-limiting conditions are either located on the extracellular medium or are associated with the plasma membrane or cell wall $[15,22]$. Corroborating with this hypothesis, Kneipp et al. [22] demonstrated that conidial forms of F. pedrosoi has an ectophosphatase activity modulated by exogenous phosphate. It seems that in F. pedrosoi, conidial cells that were cultivated in a Pi-depleted medium had an ectophosphatase 
activity significantly higher than that of fungal cells grown in the complete medium. These cells expressing high phosphatase activity were significantly more capable of adhering to epithelial cells and fibroblasts than fungi expressing basal levels of enzyme activity [22]. It was then proposed that the removal of phosphate groups from surface proteins in host cells could result in conformational transitions and in an attenuated electrostatic repulsion between fungal and epithelial cells. Probably, the removal of inorganic phosphate could therefore expose at the host surface additional sites for interaction with infectious agents. It seems that ectophosphatases may contain adhesive domains that could directly promote the attachment of fungal cells to their hosts, therefore functioning similarly to the well-characterized microbial adhesins. Probably, they could regulate the functional activation of surface adhesins, which would be the key structures mediating fungal attachment. Intriguingly, known activators of signaling pathways and cell differentiation, PAF and propanolol, promoted an enhancement of $F$. pedrosoi ectophosphatase activity [17] suggesting that F. pedrosoi ectophosphatase may be considered a surface marker for morphological transition and infection.

In the fungus C. neoformans a thick capsule composed of neutral and charged polysaccharides [70], can be modulated by different environmental conditions, including the sites of fungal infection inside the host. It seems that the molecules coating the outer layer of the cell wall could be relevant during the interaction of poorly encapsulated cells with host tissues. Ectoenzymes possibly have their accessibility to external receptors masked by the capsule polysaccharides of C. neoformans, diminishing the potential of these structures to be surface molecules influencing the interaction between fungal and host cells. In fact, different isolates of $C$. neoformans express ectophosphatase activity [23]. However, the levels of enzyme activity, varied considerably among the isolates and no correlation between enzyme activity and capsular size or serotype was observed. Evidences show that isolates with capsular polysaccharides of the same serotype varied greatly in ectophosphatase activity. In addition, the strain, which is poorly encapsulated, removed phosphate groups much more efficiently than strain, which expresses a large capsule, indicating that the presence of the capsule impairs enzyme activity in this process. On the other hand, some encapsulated strains presented levels of ectophosphatase activity higher than that observed in the acapsular mutant. Moreover, some strains that had very similar levels of enzyme activity, but differ greatly in capsule size were also found [23]. Taken together, these data indicate that differences observed in enzyme activity should be derived from natural variation of ectophosphatase expression in different $C$. noeformans strains. Corroborating with the previous findings, Kiffer-Moreira et al. [19] investigated three different isolates of $C$. parapsilosis, including a laboratoryadapted strain (CCT 3834) and two recently isolated strains (RFO and H297). They observed that the RFO strain exhibits the highest levels of enzyme activity and adhesion to $\mathrm{CHO}$ cells, followed by the H297 and the CCT 3834 isolates. Pretreatment of yeasts with the irreversible inhibitor sodium orthovanadate caused a significant reduction in the ability of these fungi to attach to epithelial cells [19]. Although sodium orthovanadate can affect different biological processes [71] and inhibit ATPases involved in cation transport [72, 73], its major biological activity in living cells occur on the cell surface, as the oxidation-reduction reactions that take place in the cytoplasm diminish its inhibitory effect. C.parapsilosis ectophosphatase may be considered an important virulence factor. Similarly, C. albicans isolate from oral cavities of HIVinfected children $\left(\mathrm{HIV}^{+}\right)$present an ectophosphatase activity significantly higher than the HIV-negative children $\left(\mathrm{HIV}^{-}\right)$ [20]. The C. albicans yeasts from $\mathrm{HIV}^{+}$patients showed higher indices of adhesion to epithelial cells, which suggests that the activity of fungal acidic surface phosphatases may contribute to the early mechanisms required for disease establishment [20]. It is reasonable the hypothesis that ectophosphatases represent a virulence marker, since these enzymes represent part of the outer layer and are linked to cell differentiation and host cell-pathogen interactions.

\section{Concluding Remarks}

The balance of phosphorylation-dephosphorylation of serine, threonine and tyrosine residues modulates signaling pathways critical for determining the outcome of multiple cellular functions [74]. Ecto-phosphatases are enzymes able to hydrolyze phosphorylated substrates in the extracellular medium. Further studies are warranted to resolve the roles of ectophosphatases in host-pathogen interactions, as well as the possible correlations between the expression of these enzymes and the clinical manifestation of the diseases.

\section{Acknowledgments}

Part of the work mentioned in this review was supported by grants from the Brazilian Agencies Conselho Nacional de Desenvolvimento Científico e Tecnológico (CNPq), Coordenação de Aperfeiçoamento de Pessoal de Nível Superior (CAPES), Fundação de Amparo à Pesquisa do Estado do Rio de Janeiro (FAPERJ), and Instituto Nacional de Ciência e Tecnologia de Biologia Estrutural e Bioimagem (INCTBEB).

\section{References}

[1] C. J. Oliver and S. Shenolikar, "Physiologic importance of protein phosphatase inhibitors," Frontiers in Bioscience, vol. 3 , pp. D961-D972, 1998.

[2] P. Cohen, “The origins of protein phosphorylation," Nature Cell Biology, vol. 4, no. 5, pp. E127-E130, 2002.

[3] T. Hunter, "Protein kinases and phosphatases: the yin and yang of protein phosphorylation and signaling," Cell, vol. 80, no. 2, pp. 225-236, 1995.

[4] M. Parsons, E. A. Worthey, P. N. Ward, and J. C. Mottram, "Comparative analysis of the kinomes of three pathogenic trypanosomatids: Leishmania major, Trypanosoma brucei and Trypanosoma cruzi," BMC Genomics, vol. 6, pp. 127-145, 2005.

[5] R. Brenchley, H. Tariq, H. McElhinney et al., "The TriTryp phosphatome: analysis of the protein phosphatase catalytic domains," BMC Genomics, vol. 8, pp. 434-455, 2007. 
[6] M. J. M. Alves and W. Colli, "Trypanosoma cruzi: adhesion to the host cell and intracellular survival," IUBMB Life, vol. 59, no. 4-5, pp. 274-279, 2007.

[7] J. R. Meyer-Fernandes, "Ecto-ATPases in protozoa parasites: looking for a function," Parasitology International, vol. 51, no. 3, pp. 299-303, 2002.

[8] J. R. Meyer-Fernandes, D. Cosentino-Gomes, D. P. Vieira, and A. H. Lopes, "Ecto-nucleoside triphosphate diphosphohydrolase activities in trypanosomatids: possible roles in infection, virulence and purine recycling," The Open Parasitology Journal, vol. 4, pp. 116-119, 2010.

[9] B. Szöör, "Trypanosomatid protein phosphatases," Molecular and Biochemical Parasitology, vol. 173, pp. 53-63, 2010.

[10] A. V. Andreeva and M. A. Kutuzov, "Protozoan protein tyrosine phosphatases," International Journal for Parasitology, vol. 38, no. 11, pp. 1279-1295, 2008.

[11] E. E. D. Almeida-Amaral, R. Belmont-Firpo, M. A. VannierSantos, and J. R. Meyer-Fernandes, "Leishmania amazonensis: characterization of an ecto-phosphatase activity," Experimental Parasitology, vol. 114, no. 4, pp. 334-340, 2006.

[12] S. A. O. Gomes, A. L. Fonseca-de-Souza, B. A. Silva et al., "Trypanosoma rangeli: differential expression of cell surface polypeptides and ecto-phosphatase activity in short and long epimastigote forms," Experimental Parasitology, vol. 112, no. 4, pp. 253-262, 2006.

[13] A. L. Fonseca-de-Souza, C. F. Dick, A. L. A. dos Santos, and J. R. Meyer-Fernandes, "A $\mathrm{Mg}^{2+}$-dependent ecto-phosphatase activity on the external surface of Trypanosoma rangeli modulated by exogenous inorganic phosphate," Acta Tropica, vol. 107, no. 2, pp. 153-158, 2008.

[14] A. L. Fonseca-de-Souza, C. F. Dick, A. L. A. dos Santos, F. V. Fonseca, and J. R. Meyer-Fernandes, "Trypanosoma rangeli: a possible role for ecto-phosphatase activity on cell proliferation," Experimental Parasitology, vol. 122, no. 3, pp. 242-246, 2009.

[15] C. F. Dick, A. L. A. dos-Santos, A. L. Fonseca-de-Souza, J. Rocha-Ferreira, and J. R. Meyer-Fernandes, "Trypanosoma rangeli: differential expression of ecto-phosphatase activities in response to inorganic phosphate starvation," Experimental Parasitology, vol. 124, no. 4, pp. 386-393, 2010.

[16] A. T. Remaley, D. B. Kuhns, and R. E. Basford, "Leishmanial phosphatase blocks neutrophil O-2 production," The Journal of Biological Chemistry, vol. 259, no. 18, pp. 11173-11175, 1984.

[17] D. S. Alviano, L. F. Kneipp, A. H. Lopes et al., "Differentiation of Fonsecaea pedrosoi mycelial forms into sclerotic cells is induced by platelet-activating factor," Research in Microbiology, vol. 154, no. 10, pp. 689-695, 2003.

[18] T. Furuya, L. I. Zhong, J. R. Meyer-Fernandes, H. G. Lu, S. N. J. Moreno, and R. Docampo, "Ecto-protein tyrosine phosphatase activity in Trypanosoma cruzi infective stages," Molecular and Biochemical Parasitology, vol. 92, no. 2, pp. 339348, 1998.

[19] T. Kiffer-Moreira, A. A. D. S. Pinheiro, W. S. Alviano et al., "An ectophosphatase activity in Candida parapsilosis influences the interaction of fungi with epithelial cells," FEMS Yeast Research, vol. 7, no. 4, pp. 621-628, 2007.

[20] M. B. Portela, L. F. Kneipp, I. P. Ribeiro De Souza et al., "Ectophosphatase activity in Candida albicans influences fungal adhesion: study between HIV-positive and HIV-negative isolates," Oral Diseases, vol. 16, no. 5, pp. 431-437, 2010.

[21] E. Touati, E. Dassa, J. Dassa, and P. L. Boquet, "Acid phosphatase (pH2.5) of Escherichia coli: regulatory characteristics," in Microorganisms, A. Torriani- Gorini, F. G. Rothman, S.
Silver, A. Wright, and E. Yagil, Eds., pp. 31-40, ASM Press, Washington, DC, USA, 1987.

[22] L. F. Kneipp, M. L. Rodrigues, C. Holandino et al., "Ectophosphatase activity in conidial forms of Fonsecaea pedrosoi is modulated by exogenous phosphate and mediates fungal adhesion to epithelial cells," Microbiology, vol. 150, pp. 33553362, 2004.

[23] I. Collopy-Junior, F. F. Esteves, L. Nimrichter, M. L. Rodrigues, C. S. Alviano, and J. R. Meyer-Fernandes, "An ectophosphatase activity in Cryptococcus neoformans," FEMS Yeast Research, vol. 6, no. 7, pp. 1010-1017, 2006.

[24] A. Martiny, M. A. Vannier-Santos, V. M. Borges et al., "Leishmania-induced tyrosine phosphorylation in the host macrophage and its implication to infection," European Journal of Cell Biology, vol. 71, no. 2, pp. 206-215, 1996.

[25] J. M. Jadin and J. Creemers, "The role of excretion of acid phosphatase in Trypanosoma brucei and T. cruzi," Transactions of the Royal Society of Tropical Medicine and Hygiene, vol. 66, no. 1, pp. 8-9, 1972.

[26] L. O. Andrade and N. W. Andrews, "Opinion: the Trypanosoma cruzi-host-cell interplay: location, invasion, retention," Nature Reviews Microbiology, vol. 3, no. 10, pp. 819-823, 2005.

[27] J. A. Atwood, D. B. Weatherly, T. A. Minning et al., "Microbiology: the Trypanosoma cruzi proteome," Science, vol. 309, no. 5733, pp. 473-476, 2005.

[28] J. McLaughlin, "The association of distinct acid phosphatases with the flagella pocket and surface membrane fractions obtained from bloodstream forms of Trypanosoma rhodesiense," Molecular and Cellular Biochemistry, vol. 70, no. 2, pp. 177-184, 1986.

[29] O. M. Tosomba, T. H. T. Coetzer, and J. D. Lonsdale-Eccles, "Localisation of acid phosphatase activity on the surface of bloodstream forms of Trypanosoma congolense," Experimental Parasitology, vol. 84, no. 3, pp. 429-438, 1996.

[30] E. C. Fernandes, J. R. Meyer-Fernandes, M. A. C. Silva-Neto, and A. E. Vercesi, "Trypanosoma brucei: ecto-phosphatase activity present on the surface of intact procyclic forms," Zeitschrift fur Naturforschung Section C-Journal of Biosciences, vol. 52, no. 5-6, pp. 351-358, 1997.

[31] N. Bakalara, X. Santarelli, C. Davis, and T. Baltz, "Purification, cloning, and characterization of an acidic ectoprotein phosphatase differentially expressed in the infectious bloodstream form of Trypanosoma brucei," The Journal of Biological Chemistry, vol. 275, no. 12, pp. 8863-8871, 2000.

[32] J. R. Meyer-Fernandes, M. A. Da Silva-Neto, M. Dos Santos Soares, E. Fernandas, A. E. Vercesi, and M. M. de Oliveira, "Ecto-phosphatase activities on the cell surface of the amastigote forms of Trypanosoma cruzi," Zeitschrift fur Naturforschung-Section C Journal of Biosciences, vol. 54, no. 11, pp. 977-984, 1999.

[33] D. Cosentino-Gomes, T. Russo-Abrahão, A. L. Fonseca-deSouza, C. R. Ferreira, A. Galina, and J. R. Meyer-Fernandes, "Modulation of Trypanosoma rangeli ecto-phosphatase activity by hydrogen peroxide," Free Radical Biology and Medicine, vol. 47, no. 2, pp. 152-158, 2009.

[34] N. Bakalara, A. Seyfang, C. Davis, and T. Baltz, "Characterization of a life-cycle-stage-regulated membrane protein tyrosine phosphatase in Trypanosoma brucei," European Journal of Biochemistry, vol. 234, no. 3, pp. 871-877, 1995.

[35] P. M. L. Dutra, C. O. Rodrigues, J. B. Jesus, A. H. C. S. Lopes, T. Souto-Padrón, and J. R. Meyer-Fernandes, "A 
novel ecto-phosphatase activity of herpetomonas muscarum muscarum inhibited by platelet-activating factor," Biochemical and Biophysical Research Communications, vol. 253, no. 1, pp. 164-169, 1998.

[36] P. M. L. Dutra, C. O. Rodrigues, A. Romeiro et al., "Characterization of ectophosphatase activities in trypanosomatid parasites of plants," Phytopathology, vol. 90, no. 9, pp. 10321038, 2000.

[37] P. M. L. Dutra, F. A. Dias, M. A. A. Santos et al., "Secreted phosphatase activities in trypanosomatid parasites of plants modulated by platelet-activating factor," Phytopathology, vol. 91, no. 4, pp. 408-414, 2001.

[38] M. M. Aguirre-García, J. Cerbón, and P. Talamás-Rohana, "Purification and properties of an acid phosphatase from Entamoeba histolytica HM-1:IMSS," International Journal for Parasitology, vol. 30, no. 5, pp. 585-591, 2000.

[39] J. N. Amazonas, D. Cosentino-Gomes, A. Werneck-Lacerda et al., "Giardia lamblia: characterization of ecto-phosphatase activities," Experimental Parasitology, vol. 121, no. 1, pp. 1521, 2009.

[40] J. De Jesus, T. Podlyska, A. Hampshire, C. Lopes, M. VannierSantos, and J. Meyer-Fernandes, "Characterization of an ecto-phosphatase activity in the human parasite Trichomonas vaginalis," Parasitology Research, vol. 88, no. 11, pp. 991-997, 2002.

[41] A. M. Shakarian, M. B. Joshi, E. Ghedin, and D. M. Dwyer, "Molecular dissection of the functional domains of a unique, tartrate-resistant, surface membrane acid phosphatase in the primitive human pathogen Leishmania donovani," The Journal of Biological Chemistry, vol. 277, no. 20, pp. 17994-18001, 2002.

[42] M. M. Aguirre-García, A. R. Escalona-Montaño, N. Bakalara, A. Pérez-Torres, L. Gutiérrez-Kobeh, and I. Becker, "Leishmania major: detection of membrane-bound protein tyrosine phosphatase," Parasitology, vol. 132, no. 5, pp. 641-649, 2006.

[43] E. C. Fernandes, J. M. Granjeiro, E. M. Taga, J. R. MeyerFernandes, and H. Aoyama, "Phosphatase activity characterization on the surface of intact bloodstream forms of Trypanosoma brucei," FEMS Microbiology Letters, vol. 220, no. 2, pp. 197-206, 2003.

[44] E. C. Fernandes, J. M. Granjeiro, H. Aoyama, F. V. Fonseca, J. R. Meyer-Fernandes, and A. E. Vercesi, "A metallo phosphatase activity present on the surface of Trypanosoma brucei procyclic forms," Veterinary Parasitology, vol. 118, no. 1-2, pp. 19-28, 2003.

[45] B. Menz, G. Winter, T. Ilg, F. Lottspeich, and P. Overath, "Purification and characterization of a membrane-bound acid phosphatase of Leishmania mexicana," Molecular and Biochemical Parasitology, vol. 47, no. 1, pp. 101-108, 1991.

[46] M. Wiese, O. Berger, Y. D. Stierhof, M. Wolfram, M. Fuchs, and P. Overath, "Gene cloning and cellular localization of a membrane-bound acid phosphatase of Leishmania mexicana," Molecular and Biochemical Parasitology, vol. 82, no. 2, pp. 153$165,1996$.

[47] M. Engstler, F. Weise, K. Bopp et al., "The membranebound histidine acid phosphatase TbMBAP1 is essential for endocytosis and membrane recycling in Trypanosoma brucei," Journal of Cell Science, vol. 118, no. 10, pp. 2105-2118, 2005.

[48] P. M. L. Dutra, L. C. Couto, A. H. C. S. Lopes, and J. R. MeyerFernandes, "Characterization of ecto-phosphatase activities of Trypanosoma cruzi: a comparative study between Colombiana and Y strains," Acta Tropica, vol. 100, no. 1-2, pp. 88-95, 2006.
[49] T. C. A. Jorge, H. S. Barbosa, A. L. Moreira, W. De Souza, and M. N. L. Meirelles, "The interaction of myotropic and macrophagotropic strains of Trypanosoma cruzi with myoblasts and fibers of skeletal muscle," Zeitschrift für Parasitenkunde Parasitology Research, vol. 72, no. 5, pp. 577-584, 1986.

[50] C. O. Rodrigues, P. M. L. Dutra, F. S. Barros, T. Souto-Padrón, J. R. Meyer-Fernandes, and A. H. C. S. Lopes, "Plateletactivating factor induction of secreted phosphatase activity in Trypanosoma cruzi," Biochemical and Biophysical Research Communications, vol. 266, no. 1, pp. 36-42, 1999.

[51] A. Martiny, J. R. Meyer-Fernandes, W. De Souza, and M. A. Vannier-Santos, "Altered tyrosine phosphorylation of ERK1 MAP kinase and other macrophage molecules caused by Leishmania amastigotes," Molecular and Biochemical Parasitology, vol. 102, no. 1, pp. 1-12, 1999.

[52] M. A. Vannier-Santos, A. Martiny, J. R. Meyer-Fernandes, and W. De Souza, "Leishmanial protein kinase C modulates host cell infection via secreted acid phosphatase," European Journal of Cell Biology, vol. 67, no. 2, pp. 112-119, 1995.

[53] D. Nandan, R. Lo, and N. E. Reiner, "Activation of phosphotyrosine phosphatase activity attenuates mitogen- activated protein kinase signaling and inhibits c-FOS and nitric oxide synthase expression in macrophages infected with Leishmania donovani," Infection and Immunity, vol. 67, no. 8, pp. 40554063, 1999.

[54] M. A. Gomez, I. Contreras, M. Hallé, M. L. Tremblay, R. W. McMaster, and M. Olivier, "Leishmania GP63 alters host signaling through cleavage-activated protein tyrosine phosphatases," Science Signaling, vol. 2, no. 90, p. ra58, 2009.

[55] I. Abu-Dayyeh, K. Hassani, E. R. Westra, J. C. Mottram, and M. Olivier, "Comparative study of the ability of Leishmania mexicana promastigotes and amastigotes to alter macrophage signaling and functions," Infection and Immunity, vol. 78, no. 6, pp. 2438-2445, 2010.

[56] D. E. Cool and J. J. Blum, "Protein tyrosine phosphatase activity in Leishmania donovani," Molecular and Cellular Biochemistry, vol. 127-128, pp. 143-149, 1993.

[57] M. Nascimento, W. W. Zhang, A. Ghosh et al., "Identification and characterization of a protein-tyrosine phosphatase in Leishmania: involvement in virulence," The Journal of Biological Chemistry, vol. 281, no. 47, pp. 36257-36268, 2006.

[58] M. Anaya-Ruiz, J. L. Rosales-Encina, and P. Talamas-Rohana, "Membrane acid phosphatase (MAP) from Entamoeba histolytica," Archives of Medical Research, vol. 28, pp. 182-183, 1997.

[59] M. M. Aguirre-García, J. Cerbón, and P. Talamás-Rohana, "Purification and properties of an acid phosphatase from Entamoeba histolytica HM-1:IMSS," International Journal for Parasitology, vol. 30, no. 5, pp. 585-591, 2000.

[60] M. M. Aguirre-Garcia, J. L. Rosales-Encina, and P. TalamasRohana, "Secreted Entamoeba histolytica acid phosphatase (SAP)," Archives of Medical Research, vol. 28, pp. 184-185, 1997.

[61] J. Ventura-Juarez, M. M. Aguirre-Garcia, and P. TalamasRohana, "Subcellular distribution and in situ localization of the acid phosphatase of Entamoeba histolytica," Archives of Medical Research, vol. 31, no. 4, pp. S183-S184, 2000.

[62] A. A. de Sá Pinheiro, J. N. Amazonas, F. de Souza Barros et al., "Entamoeba histolytica: an ecto-phosphatase activity regulated by oxidation-reduction reactions," Experimental Parasitology, vol. 115, no. 4, pp. 352-358, 2007. 
[63] L. Nimrichter, M. L. Rodrigues, E. G. Rodrigues, and L. R. Travassos, "The multitude of targets for the immune system and drug therapy in the fungal cell wall," Microbes and Infection, vol. 7, no. 4, pp. 789-798, 2005.

[64] P. Mildner, B. Ries, and S. Barbaric, "Acid phosphatase and adenosine triphosphatase activities in the cell wall of baker's yeast," Biochimica et Biophysica Acta, vol. 391, no. 1, pp. 6774, 1975.

[65] P. H. Fernanado, G. J. Panagoda, and L. P. Samaranayake, "The relationship between the acid and alkaline phosphatase activity and the adherence of clinical isolates of Candida parapsilosis to human buccal epithelial cells," APMIS, vol. 107, pp. 1034-1042, 1999.

[66] W. N. Arnold, L. C. Mann, and K. H. Sakai, "Acid phosphatases of Sporothrix schenckii," Journal of General Microbiology, vol. 132, no. 12, pp. 3421-3432, 1986.

[67] M. Bernard, I. Mouyna, G. Dubreucq et al., "Characterization of a cell-wall acid phosphatase (PhoAp) in Aspergillus fumigatus," Microbiology, vol. 148, no. 9, pp. 2819-2829, 2002.

[68] L. F. Kneipp, V. F. Palmeira, A. A. S. Pinheiro et al., "Phosphatase activity on the cell wall of Fonsecaea pedrosoi," Medical Mycology, vol. 41, no. 6, pp. 469-477, 2003.

[69] T. Kiffer-Moreira, A. A. S. Pinheiro, M. R. Pinto et al., "Mycelial forms of Pseudallescheria boydii present ectophosphatase activities," Archives of Microbiology, vol. 188, no. 2, pp. 159-166, 2007.

[70] I. Bose, A. J. Reese, J. J. Ory, G. Janbon, and T. L. Doering, "A yeast under cover: The capsule of Cryptococcus neoformans," Eukaryotic Cell, vol. 2, no. 4, pp. 655-663, 2003.

[71] J. K. Klarlund, "Transformation of cells by an inhibitor of phosphatases acting on phosphotyrosine in proteins," Cell, vol. 41, no. 3, pp. 707-717, 1985.

[72] C. L. Sodré, B. L. M. Moreira, F. B. Nobrega et al., "Characterization of the intracellular $\mathrm{Ca}^{2+}$ pools involved in the calcium homeostasis in Herpetomonas sp. promastigotes," Archives of Biochemistry and Biophysics, vol. 380, no. 1, pp. 85-91, 2000.

[73] E. E. de Almeida-Amaral, C. Caruso-Neves, V. M. P. Pires, and J. R. Meyer-Fernandes, "Leishmania amazonensis: characterization of an ouabain-insensitive $\mathrm{Na}^{+}$-ATPase activity," Experimental Parasitology, vol. 118, no. 2, pp. 165-171, 2008.

[74] D. Cosentino-Gomes and J. R. Meyer-Fernandes, "Ectophosphatases in protozoan parasites: possible roles in nutrition, growth and ROS sensing," Journal of Bioenergetics and Biomembranes, vol. 43, no. 1, pp. 89-92, 2011. 

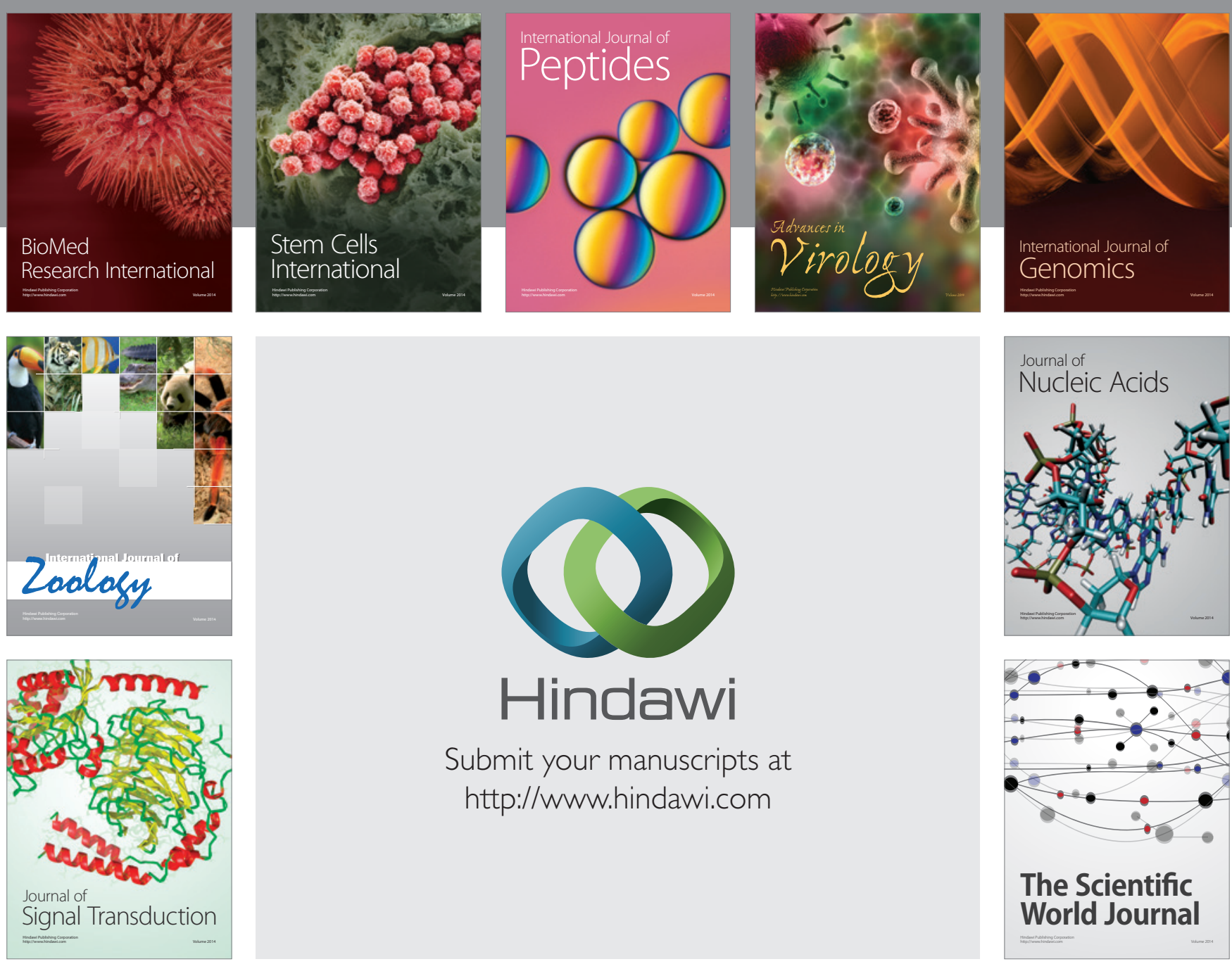

Submit your manuscripts at

http://www.hindawi.com
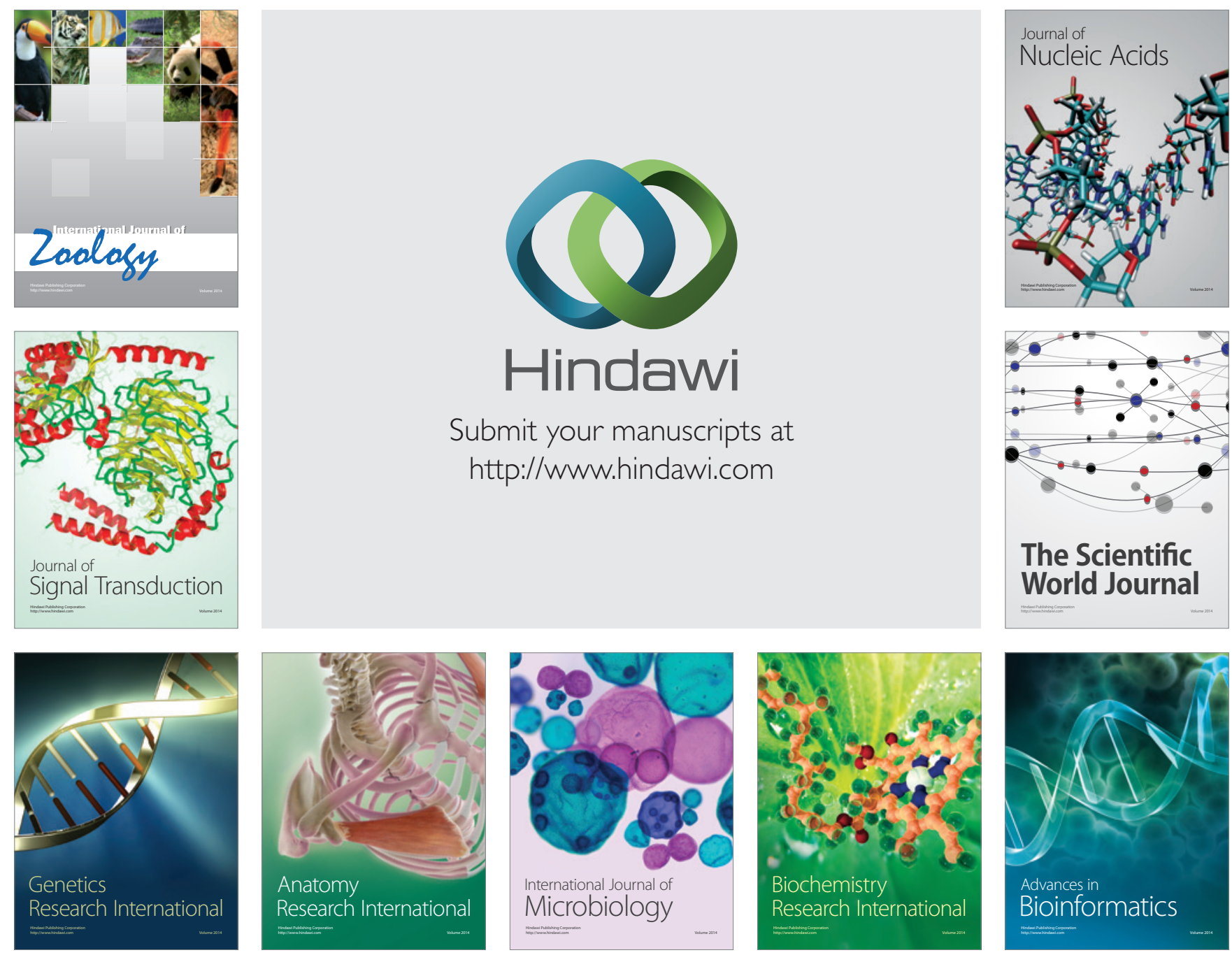

The Scientific World Journal
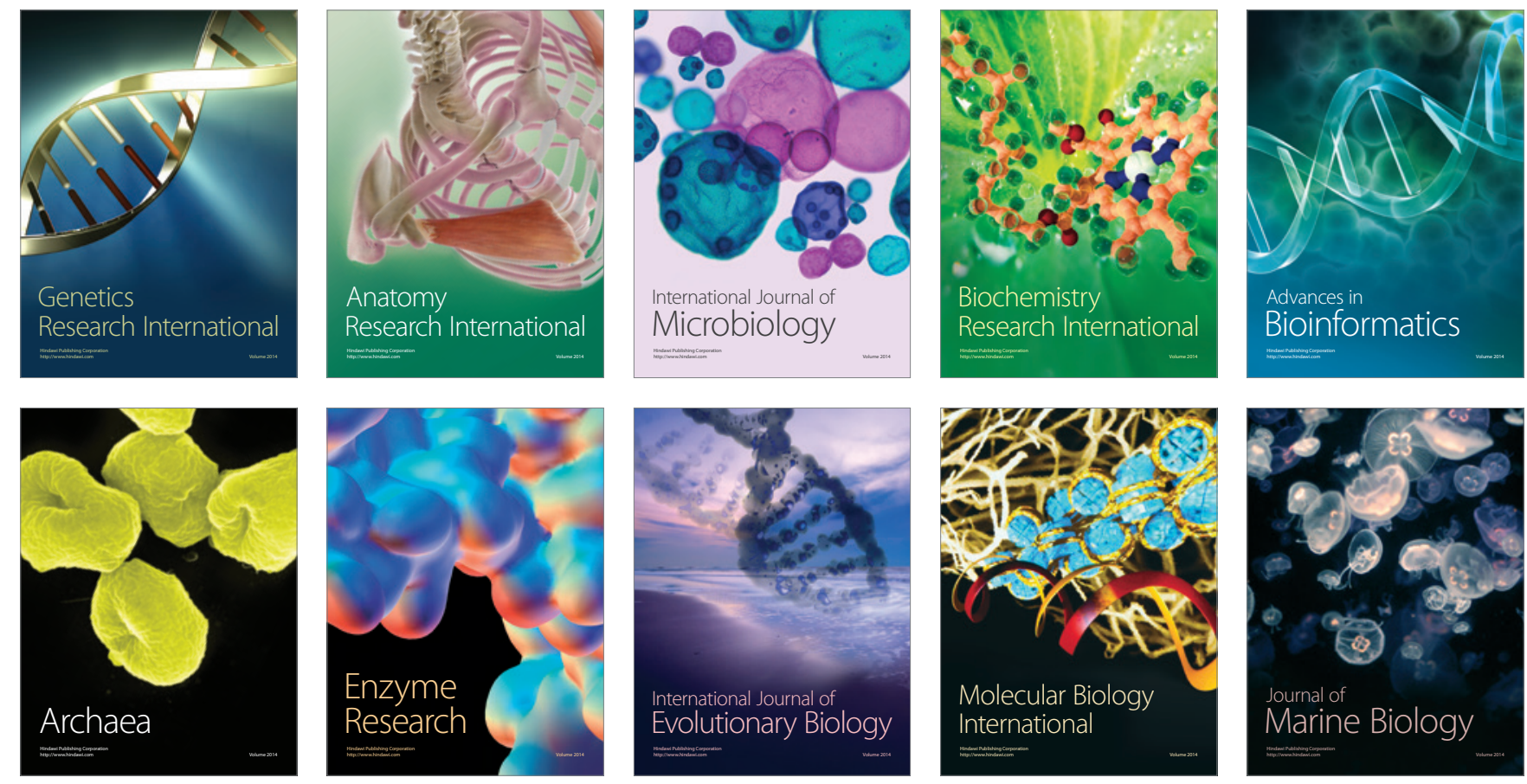